\title{
Management in non-traumatic arm, neck and shoulder complaints: differences between diagnostic groups
}

\author{
Anita Feleus · Sita M. A. Bierma-Zeinstra • \\ Harald S. Miedema - Jan A. N. Verhaar . \\ Bart W. Koes
}

Received: 21 October 2007/Revised: 21 February 2008/Accepted: 18 June 2008/Published online: 8 July 2008

(C) The Author(s) 2008

\begin{abstract}
Arm, neck and/or shoulder complaints are common in western societies. In the Netherlands, general practice guidelines are issued on shoulder pain and epicondylitis only. Little is known about actual management of the total range of diagnoses. The objectives of the study are: to determine management in patients consulting the GP with a new episode of non-traumatic arm neck and shoulder complaints up to 6 months after the first consultation. To evaluate differences in management between patients with specific diagnoses versus non-specific diagnoses and between specific diagnostic groups. In a prospective cohort study in general practice. We recruited 682 eligible patients. Data on diagnosis, management, patient- and complaintcharacteristics were collected. Co-occurrence of treatment options was presented in scaled rectangles. After 6 months,
\end{abstract}

All authors declare that they participated in the writing and editing of the manuscript and that they have read and approved the final version.

\section{A. Feleus $(\bowtie)$}

Department of General Practice, Erasmus MC, Room Wk121, PO Box 2040, 3000 CA Rotterdam, The Netherlands

e-mail: a.feleus@erasmusmc.nl

\section{S. M. A. Bierma-Zeinstra}

Department of General Practice, Erasmus MC, Room Ff320,

PO Box 2040, 3000 CA Rotterdam, The Netherlands

A. Feleus · H. S. Miedema

Netherlands Expert Center for Work-related Musculoskeletal

Disorders, Erasmus MC, Rotterdam, The Netherlands

\section{J. A. N. Verhaar}

Department of Orthopaedics, Erasmus MC, Rotterdam,

The Netherlands

B. W. Koes

Department of General Practice, Erasmus MC, PO Box 2040, 3000 CA Rotterdam, The Netherlands additional diagnostic tests had been performed in $18 \%$ of the patients, mainly radiographic examination (14\%). Further, $49 \%$ had been referred for physiotherapy and $12 \%$ to the medical specialist. Patients with specific diagnoses were more frequently referred for specialist treatment, and patients with non-specific diagnoses for physiotherapy. Corticosteroid injections (17\%) were mainly applied specific diagnoses (e.g. impingement syndrome, frozen shoulder, carpal tunnel and M. Quervain). Frequencies of prescribed medication $(51 \%)$ did not differ between specific and non-specific diagnoses. In $19 \%$ of the patients no referral, prescribed analgesics or injection was applied. Braces (4\%) were mainly prescribed in epicondylitis. Overall, management most frequently consisted of prescribed analgesics and referral for physiotherapy. Specific and non-specific diagnostic subgroups differed in the frequency corticosteroid injections were applied, and referrals to physiotherapy and to a medical specialist.

Keywords Arm · Neck $\cdot$ Shoulder $\cdot$ Treatment . General practice

\section{Introduction}

Complaints of arm, neck and shoulder are very common in Western societies [21, 29]. In the Netherlands, the 12 months prevalence in the general population has been estimated at $31.4 \%$ for neck pain, $30.3 \%$ for shoulder pain, $11.2 \%$ for elbow pain and $17.5 \%$ for wrist or hand pain [21].

The general practitioner (GP) is often consulted for these complaints [12, 21, 22].

Studies in the general population in Norway reported that $45 \%$ of the adults with non-inflammatory musculoskeletal pain consulted a GP in the previous 12 months 
[12]. In persons with arm, neck and shoulder pain in the Netherlands, this was about $30-40 \%$ [21].

Incidence figures in patients (aged 18-64 years) with nontraumatic arm, neck or shoulder complaints in Dutch general practice, reported 97 consultations per 1,000 registered persons annually. This indicates approximately three consultations per week in an average practice with 2,350 patients [10].

Among the prominent factors in patients with musculoskeletal pain associated with consultation of a GP [12, 19] or healthcare in general [8] are: high pain intensity [8, 12], much disability [8], sickness absence [12, 19], long duration of the complaint [12, 19] and widespread pain [12]. Thus, when people feel hindered by their complaints, they are more likely to consult their GP.

To define upper extremity musculoskeletal disorders (not caused by acute trauma or systemic disease) a multidisciplinary consensus was recently reached in the Netherlands. The aim was to help professionals classify patients unambiguously and to improve communication amongst health care workers. Within these complaints, 23 disorders were classified as specific because they were judged as diagnosable disorders by experts [15].

Distinction between diagnostic groups is important if these groups have different prognoses or require different management decisions.

For management in these complaints, guidelines issued by the Dutch College of General Practitioners are only available for patients diagnosed with epicondylitis and shoulder pain [1, 2].

So far, no studies reported on how non-traumatic arm, neck and shoulder complaints are managed after a patient consults his/her GP, nor compared management between different diagnostic groups (such as: shoulder impingement, carpal tunnel syndrome, epicondylitis and non-specific neckshoulder pain). Therefore, data on management can help to define usual care in these complaints, or may show that there is a large variation in care. This insight may serve as information important for future trials, providing evidence of efficacy of the various treatments used and their cost utility.

Our objectives are: to determine management in patients consulting the GP with a new episode of non-traumatic arm neck and shoulder complaints up to 6 months after the first consultation. To evaluate differences in management between patients with specific diagnoses versus non-specific diagnoses and between specific diagnostic groups.

\section{Methods}

\section{Design and setting}

The present study was part of a larger prospective cohort study on course and management, which was performed in the Southwestern region of the Netherlands in 21 general practices.

At baseline and after 6 months, data were collected from patients by means of self-administered questionnaires.

The Medical Ethics Committee of the Erasmus Medical Center in Rotterdam approved the study protocol.

Patients

In total, 31 GPs recruited eligible patients from September 2001 through December 2002. Inclusion criteria were: patients who consulted their GP for a new complaint or new episode of complaints of neck, upper back, shoulder, upper arm, elbow, forearm, wrist or hand (age 1864 years) and able to complete Dutch language written questionnaires. The episode was considered 'new' if patients had not visited their GP for the same complaint during the preceding 6 months. We excluded patients of whom the presented complaint could be explained by a trauma, fracture, malignancy, amputation, prosthesis, congenital defect or previously diagnosed systemic and/or generalised neurological disorder.

\section{Procedures}

During the first consultation, patients received from their GP the study-information, an informed consent form, and the baseline questionnaire. A fax was sent by the GP to the investigators with a patient ID number, information on age, gender, diagnosis, recurrence and prognosis.

After the research team received the completed informed consent form and the baseline questionnaire (within 8 weeks), inclusion criteria were verified in the computerised medical records. After inclusion, the followup questionnaire was sent from the research centre at 6 months after the first consultation. Data on management and patient and complaint characteristics, were extracted from the self-administered questionnaires.

\section{Measurements}

The following variables were measured:

- Patient characteristics: age, gender, educational level and being employed.

- Complaint characteristics: duration of the complaints at the first consultation, musculoskeletal co-morbidity, non-musculoskeletal co-morbidity and recurrence. Furthermore, a complaint was defined as 'regional' or 'multiple regional', based on the area with the most pain or complaints during the last week indicated on a manikin. Three regions were defined: neck-shoulder (including neck, upper part of thoracic spine, shoulder and upper arm), elbow-fore arm and wrist-hand. 
A complaint was defined 'multiple regional' when more than one region was indicated. The diagnosis as registered by the treating GP (Appendix) was dichotomised by the researcher into specific or non-specific based on a categorisation by Sluiter et al. [23] and by a consensus procedure [15], where a diagnosis was categorised as specific when it could be attributed to a specific medically objectifiable disorder. When the GP indicated more than one diagnosis, the specific diagnosis was given priority.

- Hindrance: complaints during leisure activities, sports activities and work activities, and sick leave were registered.

Complaint severity was measured on an 11-point numerical rating scale from 0 (no complaints) to 10 (unbearable complaints).

Functional limitations of the arm, neck, shoulder or hand was measured with the Disability of Arm Shoulder and Hand (DASH) questionnaire [14]. Each item was scored on a 5-point Likert scale. Response scores were summed and transferred to a score ranging from 0 (no disability) to 100 (completely disabled).

- Management: Information on diagnostic procedures, consulted care providers and treatment received both at baseline and at 6 months was gathered by self-administered questionnaires. Participants were asked: which care provider did you consult related to this arm, neck or shoulder complaint, how often, and what treatment did you receive. The types of diagnostic procedures, if any, were also registered.

Statistical analyses

\section{Study population}

Descriptive statistics were used to present the patient, complaint, symptoms and hindrance for both the total population and the two subgroups of patients with specific or non-specific diagnoses.

Selective non-response and selective dropout among the patients was evaluated using logistic regression analysis (step backward Wald, significance level <0.05) in SPSS version 11.0 (Chicago, IL, USA). The variables on the fax form submitted by the GP (age, gender, specific diagnosis, recurrent complaint and expected prognosis of the GP) were included for the analyses on non-responders, and the baseline variables (Table 1) were used in the analyses on dropouts.

\section{Management}

Frequencies on treatment options are presented for both the total population and subsequently grouped per diagnostic category. Differences in distribution of treatment variables between the group with a specific diagnosis and non-specific diagnosis at 6 months were tested using Pearson's Chi-square (two-sided) test $P<0.05$.

In scaled rectangle diagrams [20] co-occurrence of the four main treatment options are presented for the group with specific diagnoses and non-specific diagnoses, 6 months after the first consultation. Here, co-occurrence implies that different treatments can take place at the same time or after one another within the 6-month study period.

With the exception of the scaled rectangles, all analyses were performed with SPSS, version 11.0 for Windows (SPSS Inc, Chicago, IL, USA).

To produce scaled rectangle diagrams, SPAN software was used. This was downloaded from http://www. auckland.ac.nz/mch/span.

\section{Results}

Study population

In total 798 patients fulfilled the criteria of which 682 $(85.5 \%)$ returned a completed baseline questionnaire and informed consent and entered the cohort. The mean time between consultation and filling in the questionnaire was 2 weeks.

No differences were found between responders and nonresponders on distribution of age (18-40 years $50 \%$ versus $61 \% ; P=0.09)$, males $(41 \%$ versus $44 \% ; P=0.31)$, specific diagnosis (59\% versus 54\%; $P=0.11$ ), recurrent complaint ( $28 \%$ versus $24 \% ; P=0.34$ ) or poor prognosis according to the GP (32\% versus $30 \% ; P=0.92)$.

Of all 682 participants, $42 \%$ was male and the median age was 45 years. The complaints were mainly located at the neck, upper back, shoulder or upper arm (77\%), followed by elbow-forearm (25\%) and wrist or hand (19\%), and involved more than one region in $42 \%$. Most patients reported complaints were pain when active $(86 \%)$ or in rest (52\%) (more than one is possible). About 50\% reported complaints during leisure activities, sports or work (Table 1). According to our classification, 59\% of the complaints was diagnosed as specific, mostly impingement of the shoulder (Appendix).

Between the specific and non-specific diagnostic subgroups, no differences were found in severity of complaints and functional limitations.

However, in the group with non-specific diagnoses complaints during working activities were reported more frequently, and complaints during sports activities less frequently. Stiffness was more frequently reported in the non-specific group, and loss of strength and coordination 
Table 1 Patient characteristics at baseline $(n=682)$

\begin{tabular}{|c|c|c|c|}
\hline Variables & $\begin{array}{l}\text { Specific diagnoses } \\
(n=402)\end{array}$ & $\begin{array}{l}\text { Non-specific diagnoses } \\
(n=280)\end{array}$ & $\begin{array}{l}\text { Total population } \\
(n=682)\end{array}$ \\
\hline \multicolumn{4}{|l|}{ Patient characteristics } \\
\hline Age (18-64 years), median (range) & $41(18-64)$ & $48(18-64)$ & $45(18-64)$ \\
\hline Male, $n(\%)$ & $184(46)^{\mathrm{b}}$ & $99(36)$ & $283(42)$ \\
\hline \multicolumn{4}{|l|}{ Educational level $^{\mathrm{a}}$} \\
\hline Low, $n(\%)$ & $158(39)$ & $86(31)$ & $244(36)$ \\
\hline Medium, $n(\%)$ & $141(35)$ & $102(37)$ & $243(36)$ \\
\hline High, $n(\%)$ & $103(26)$ & $91(32)$ & $194(28)$ \\
\hline Having paid work, $n(\%)$ & $310(77)$ & $224(80)$ & $534(78)$ \\
\hline \multicolumn{4}{|l|}{ Complaint characteristics } \\
\hline \multicolumn{4}{|l|}{ Duration of the complaint } \\
\hline 0-6 weeks, $n(\%)$ & $189 / 401(47)^{\mathrm{c}}$ & $155(55)$ & $344 / 681(50)$ \\
\hline 6 weeks to 6 months, $n(\%)$ & $107 / 401(27)^{\mathrm{c}}$ & $55(19)$ & $162 / 681(24)$ \\
\hline$>6$ months, $n(\%)$ & $105 / 401(26)$ & $70(25)$ & $175 / 681(26)$ \\
\hline Co-morbidity musculoskeletal, $n(\%)$ & $203(51)$ & $128(46)$ & $331(49)$ \\
\hline Co-morbidity non-musculoskeletal, $n(\%)$ & $88(22)$ & $57(20)$ & $145(21)$ \\
\hline Recurrent complaint, $n(\%)$ & $92(23)^{\mathrm{c}}$ & $99(36)$ & $191(28)$ \\
\hline \multicolumn{4}{|l|}{ Region of main complaint ${ }^{\mathrm{b}}, n(\%)$} \\
\hline Neck, upper back, shoulder, upper arm & $273(67)^{\mathrm{c}}$ & $255(91)$ & $528(77)$ \\
\hline Elbow or forearm & $133(33)^{\mathrm{c}}$ & $37(13)$ & $170(25)$ \\
\hline Wrist or hand & $87(22)^{\mathrm{c}}$ & $41(15)$ & $128(19)$ \\
\hline Multiple region complaint, $n(\%)$ & $186(46)^{\mathrm{c}}$ & $101(36)$ & $287(42)$ \\
\hline Specific complaint, $n(\%)$ & n.a. & n.a. & $402(59)$ \\
\hline \multicolumn{4}{|l|}{ Symptoms } \\
\hline Pain when active, $n(\%)$ & $350(87)$ & $234(84)$ & $584(86)$ \\
\hline Pain in rest, $n(\%)$ & $200(50)$ & $153(55)$ & $353(52)$ \\
\hline Loss of strength, $n(\%)$ & $232(58)^{\mathrm{c}}$ & $91(32)$ & $323(47)$ \\
\hline Stiffness, $n(\%)$ & $141(35)^{\mathrm{c}}$ & $152(54)$ & $293(43)$ \\
\hline Tingling, $n(\%)$ & $98(24)$ & $74(27)$ & $172(25)$ \\
\hline Numbness, $n(\%)$ & $77(19)$ & $63(23)$ & $140(21)$ \\
\hline Cold feeling shoulder, arm, hand, $n(\%)$ & $61(15)$ & $52(19)$ & $113(17)$ \\
\hline Less hand coordination, $n(\%)$ & $75(19)^{\mathrm{c}}$ & $34(12)$ & $109(16)$ \\
\hline \multicolumn{4}{|l|}{ Hindrance } \\
\hline Complaints during leisure activities, $n(\%)$ & $231 / 401(58)$ & $144 / 280(51)$ & $375 / 680(55)$ \\
\hline $\begin{array}{l}\text { Complaints during sports activities (among participants doing } \\
\text { sports, } n=302), n(\%)\end{array}$ & $108 / 182(59)^{\mathrm{c}}$ & $61 / 120(51)$ & $169 / 302(56)$ \\
\hline $\begin{array}{l}\text { Complaints during working activities (among working population, } \\
n=534), n(\%)\end{array}$ & $172 / 310(56)$ & $142 / 223(63)$ & $315 / 533(59)$ \\
\hline Related sick leave in past 6 months (working population, $n=534$ ), $n(\%)$ & $55 / 310(18)^{\mathrm{c}}$ & $72 / 224(32)$ & $127 / 534(24)$ \\
\hline Severity of complaints $(0-10)$, mean (SD) & $5.6(2.0)$ & $6.0(1.9)$ & $5.8(2.0)$ \\
\hline Functional limitations, DASH $(0-100)$, mean (SD) & $38.7(19.0)$ & $34.1(18.2)$ & $36.8(18.8)$ \\
\hline
\end{tabular}

$S D$ Standard Deviation, $n$ number of patients, n.a. not applicable, DASH disability of arm, shoulder and hand questionnaire

${ }^{a}$ Educational level: low, no education; primary school or lower vocational school; medium, lower or higher general secondary school level or middle vocational school; high, higher vocational school or university

b More than one region is possible

c Different distribution between the two subgroups. Pearson's Chi-square tested (two-sided), $P$ value $<0.05$

less frequently compared to the specific group. Further, the complaints are more frequently located in the neck-shoulder region compared to the specific group, and the elbow- forearm and wrist-hand region were less frequently involved. In non-specific diagnoses, complaints are more frequently recurrent. Additionally, distribution of duration 
of complaints differed and the percentage women was higher in the non-specific group.

\section{Selective dropout}

For 603 participants data on treatment were available at both baseline and 6 months $(88.4 \%)$.

Being a dropout was significantly related to younger age (18-44 years) (odds ratio 2.8, 1.7-4.7) and being a male (odds ratio 1.9, 1.2-3.0).

\section{Additional diagnostic tests}

At baseline, $9 \%$ of the patients reported that additional diagnostic tests (additional to history and physical examination) were performed, which was doubled after 6 months (Table 2). The diagnostic procedures were mainly radiographic examinations (14\%), followed by laboratory tests $(6 \%)$ and EMG analysis (4\%). No differences were found between the subgroups with specific versus non-specific diagnoses (Pearson $\chi^{2}=0.73$ ). In the specific diagnoses group EMG analysis was most frequently applied in patients with carpal tunnel syndrome. In specific diagnostic groups in the forearm and wrist/hand region radiology was applied in $17-30 \%$.

\section{Referral}

Of all the consulters, $26 \%$ reported to be referred at baseline, increasing up to $55 \%$ after 6 months. After 6 months, $49 \%$ was referred for physiotherapy and $12 \%$ to a medical specialist, mostly an orthopaedic surgeon $(6 \%)$ or a neurologist (5\%) (Table 3).

Patients with a non-specific diagnosis were more frequently referred to a physiotherapist (Pearson $\chi^{2}<0.0001$ ) and patients with a specific diagnosis were more frequently referred to a medical specialist (Pearson $\chi^{2}=0.014$ ). Though the largest group, subacromial impingement has the largest referral rates to specialist care; in percentages carpal tunnel syndrome and cervical hernia score relatively the highest referral rates. Furthermore, $50 \%$ of the patients diagnosed with epicondylitis were referred for physiotherapy, 6 months after the first consultation. In other specific diagnostic groups concerning tendon complaints, figures from $40-54 \%$ were reported.

In the group diagnosed with osteoarthritis of elbow/ wrist/hand, no referrals were made to a medical specialist.

Medication and braces

At baseline, 35\% received analgesics (paracetamol/ NSAID), $10 \%$ a corticosteroid injection and $1 \%$ a brace. After 6 months, 51\% prescribed analgesics, $17 \%$ had received a corticosteroid injection and $4 \%$ a brace (Table 4). Injections were more frequently applied in specific diagnoses (Pearson $\left.\chi^{2}<0.00001\right)$. The highest percentages were found in impingement syndrome, frozen shoulder, carpal tunnel syndrome and M. Quervain. Between specific and non-specific diagnoses no significant difference (borderline) was found in medication use (Pearson $\left.\chi^{2}=0.057\right)$. Braces were mostly applied in specific diagnoses (Pearson $\chi^{2}=0.006$ ), mainly in epicondylitis.

\section{Co-occurrence of different treatment options}

The four most frequently reported treatment options up to 6 months (treatment by a physiotherapist, medical specialist, prescription of analgesics or corticosteroid injection) are presented in scaled rectangle diagrams for the group with non-specific diagnoses (Fig. 1) and with specific diagnoses (Fig. 2). In the non-specific group, $21 \%$ received none of the four options, $46 \%$ received one option and $33 \%$ more than one option, mainly medication in combination with physiotherapy. In the specific group, $17 \%$ received none of the four options, $43 \%$ received one option and $40 \%$ more than one option, mainly analgesics in combination with physiotherapy. Though the percentages are similar, the specific group shows more corticosteroid injections in combination with more referrals to a medical specialist. On the whole, 112 patients (19\%) did not receive any of the four options within 6 months.

\section{Discussion}

\section{Management}

Management of non-traumatic arm, neck and shoulder complaints presented in general practice up to 6 months after the first consultation mainly consisted of prescribed analgesics $(51 \%)$ and referral to physiotherapy (49\%), followed by corticosteroid injections (17\%) and referral for medical specialist care (12\%). In $19 \%$ of the patients none of these options was applied.

Medical care in general, will most likely match the diagnosis [30] and the expected corresponding natural course [9]. From the distribution of the management options in patients diagnosed with impingement and frozen shoulder, it seems that management is in accordance with the Dutch guideline [2] that recommends a stepwise approach: i.e. information and wait and see, analgesics (ideally: paracetamol; NSAID as second line intermittently if no contraindications exist), followed by corticosteroid injections and, if functional limitations are still present after 6 weeks referral for exercise therapy. Studies on cost 


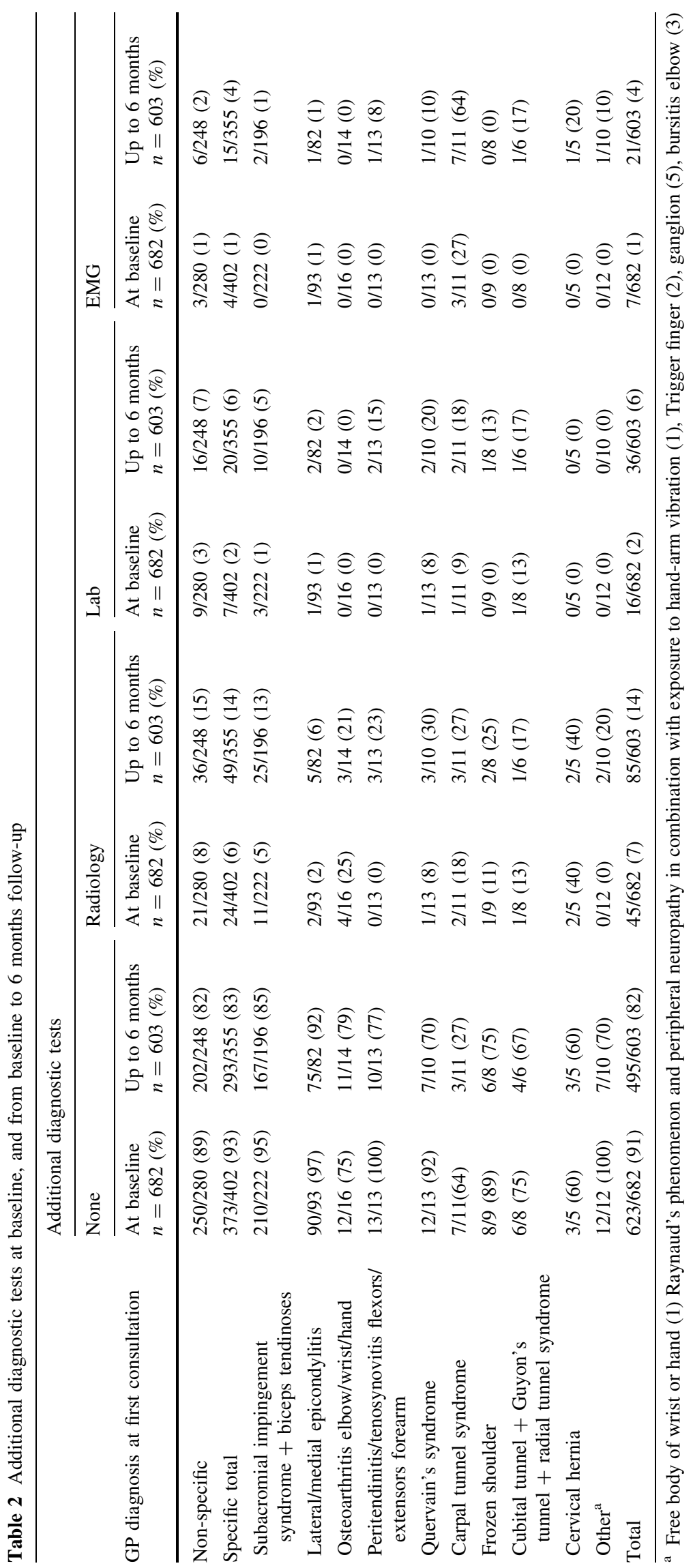


Table 3 Referrals at baseline, and from baseline to 6 months follow-up

\begin{tabular}{|c|c|c|c|c|c|c|}
\hline \multirow[b]{3}{*}{ GP diagnosis at first consultation } & \multicolumn{6}{|l|}{ Referral to } \\
\hline & \multicolumn{2}{|l|}{ None } & \multicolumn{2}{|l|}{ Physiotherapy } & \multicolumn{2}{|c|}{ Medical specialist } \\
\hline & $\begin{array}{l}\text { At baseline } \\
n=682(\%)\end{array}$ & $\begin{array}{l}\text { Up to } 6 \text { months } \\
n=603(\%)\end{array}$ & $\begin{array}{l}\text { At baseline } \\
n=682(\%)\end{array}$ & $\begin{array}{l}\text { Up to } 6 \text { months } \\
n=603(\%)\end{array}$ & $\begin{array}{l}\text { At baseline } \\
n=682(\%)\end{array}$ & $\begin{array}{l}\text { Up to } 6 \text { month } \\
n=603(\%)\end{array}$ \\
\hline Non-specific & $191 / 280(68)$ & $94 / 248(38)$ & $85 / 280(30)$ & $148 / 248(60)$ & $7 / 280(3)$ & $21 / 248(9)$ \\
\hline Specific total & $312 / 402(78)$ & $176 / 355(50)$ & $73 / 402(18)$ & $150 / 355(42)$ & $24 / 402(6)$ & $54 / 355(15)$ \\
\hline $\begin{array}{l}\text { Subacromial impingement } \\
\text { syndrome }+ \text { biceps tendinoses }\end{array}$ & $177 / 222(80)$ & $95 / 196(49)$ & $38 / 222(17)$ & $83 / 196(42)$ & $11 / 222(5)$ & 25/196 (13) \\
\hline Lateral/medial epicondylitis & $68 / 93(73)$ & $38 / 82(46)$ & $23 / 93(25)$ & $41 / 82(50)$ & $3 / 93$ & $5 / 82(6)$ \\
\hline Osteoarthritis elbow/wrist/hand & $16 / 16(100)$ & $13 / 14(93)$ & $0 / 16(0)$ & $1 / 14(7)$ & $0 / 16(0)$ & $0 / 14(0)$ \\
\hline $\begin{array}{l}\text { Peritendinitis/tenosynovitis flexors/ } \\
\text { extensors forearm }\end{array}$ & $11 / 13(85)$ & $5 / 13(39)$ & $2 / 13(15)$ & $7 / 13(54)$ & $0 / 13(0)$ & $4 / 13(31)$ \\
\hline Quervain's syndrome & $12 / 13(92)$ & $5 / 10(50)$ & $1 / 13(8)$ & $4 / 10(40)$ & $0 / 13(0)$ & $1 / 10(10)$ \\
\hline Carpal tunnel syndrome & $5 / 11(46)$ & $3 / 11(27)$ & 2/11 (18) & 2/11 (18) & $4 / 11(36)$ & $8 / 11(73)$ \\
\hline Frozen shoulder & $6 / 9(67)$ & $3 / 8(38)$ & $3 / 9(33)$ & $5 / 8(63)$ & $1 / 9(11)$ & $2 / 8(25)$ \\
\hline $\begin{array}{l}\text { Cubital tunnel + Guyon's } \\
\text { tunnel }+ \text { radial tunnel syndrome }\end{array}$ & $4 / 8(50)$ & $2 / 6(33)$ & $2 / 9(25)$ & $2 / 6(33)$ & $2 / 8(25)$ & 2/6 (33) \\
\hline Cervical hernia & $3 / 5(60)$ & $1 / 5(20)$ & $2 / 5$ & $4 / 5(80)$ & $1 / 5(20)$ & $3 / 5(60)$ \\
\hline Other $^{\mathrm{a}}$ & $10 / 12(83)$ & $5 / 10(50)$ & $0 / 12(0)$ & $1 / 10(10)$ & $2 / 12(17)$ & $4 / 10(40)$ \\
\hline Total & $503 / 682(74)$ & $270 / 603(45)$ & $158 / 682(23)$ & $298 / 603$ (49) & $31 / 682(5)$ & $75 / 603(12)$ \\
\hline
\end{tabular}

${ }^{a}$ Free body of wrist or hand (1) Raynaud's phenomenon and peripheral neuropathy in combination with exposition to hand-arm vibration (1), trigger finger (2), ganglion (5), bursitis elbow (3)

effectiveness in shoulder pain, favoured injection over physiotherapy [16].

In epicondylitis a similar approach is recommended; information and wait and see, followed by analgesics or corticosteroid injections if pain hinders function. In the present study, $46 \%$ of the patients was prescribed medication.

In the present study, $50 \%$ of the patients was referred for physiotherapy although there is no explicit recommendation for physiotherapy in the guideline [1]. Additionally, cost effectiveness studies, concluded no preference for physiotherapy over a brace [25], and no preference for physiotherapy or corticosteroid injections over "wait and see' [18]. Reasons for the large percentage of referral may be that obvious options do not give the desired results. Besides, patient's circumstances and preferences may play a role as well [13].

The low percentages of additional diagnostic tests in specific shoulder diagnoses and epicondylitis, seem in line with the practice guidelines, where additional diagnostic tests are not recommended (unless in case of deviating course or severe pathology) because the results have no consequences for management $[1,2]$.

The results of management in the small group with CTS $(n=11)$, seems to be in line with a Dutch multidisciplinary guideline published after our study closed [7].
In which is noted that a probability diagnosis of CTS can be stated in primary care based on information from history taking, and the GP can start matching treatment. Referral to secondary care is advised when complaints persist. For this relatively small group special treatment or confirmation from a medical specialist seems to be preferred.

Regarding the prescription of analgesics, we could not always distinguish between paracetamol and NSAIDs from our own data. Data from the second Dutch national survey of general practice, based on the International Classification of Primary Care, demonstrated that in many musculoskeletal complaints (ranging from shoulder complaints, arm symptoms, elbow complains, wrist and hand complaints, cervical syndromes, shoulder syndromes, epicondylitis), diclofenac is the most frequently prescribed medication [6]. Despite the rationale behind the choice for NSAIDs, analgesic potential and their inflammatory action, so far no studies evaluated the effectiveness of NSAIDs versus paracetamol (acetaminophen) or additional to paracetamol in non-traumatic arm, neck and shoulder complaints. In 1995, a review on NSAIDs in shoulder complaints already pointed out that future studies should establish whether the use of NSAIDs is more favourable than simple analgesics, especially in the light of the higher risk of adverse reactions from NSAIDs [26]. 


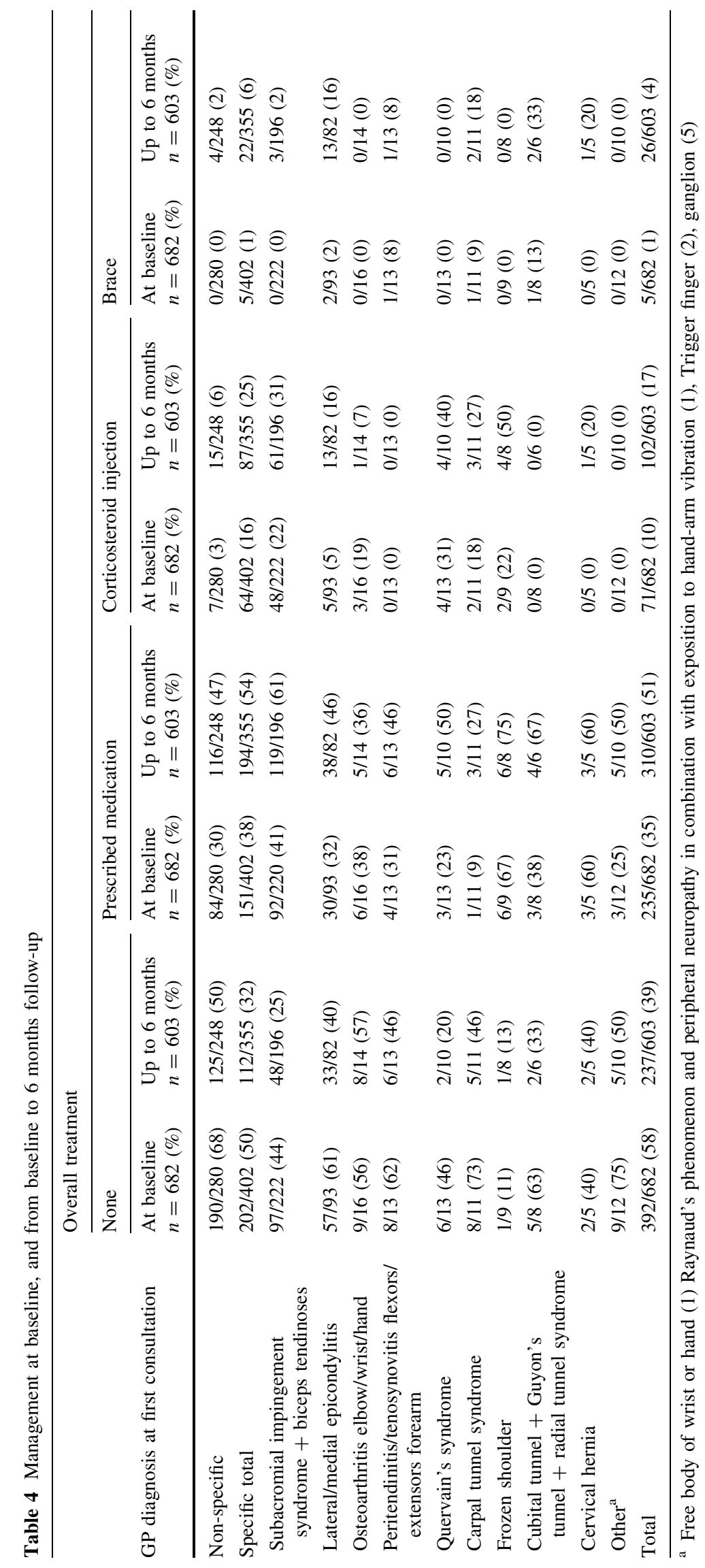


Fig. 1 Non-specific diagnoses and treatment up to 6 months after the first GP consultation

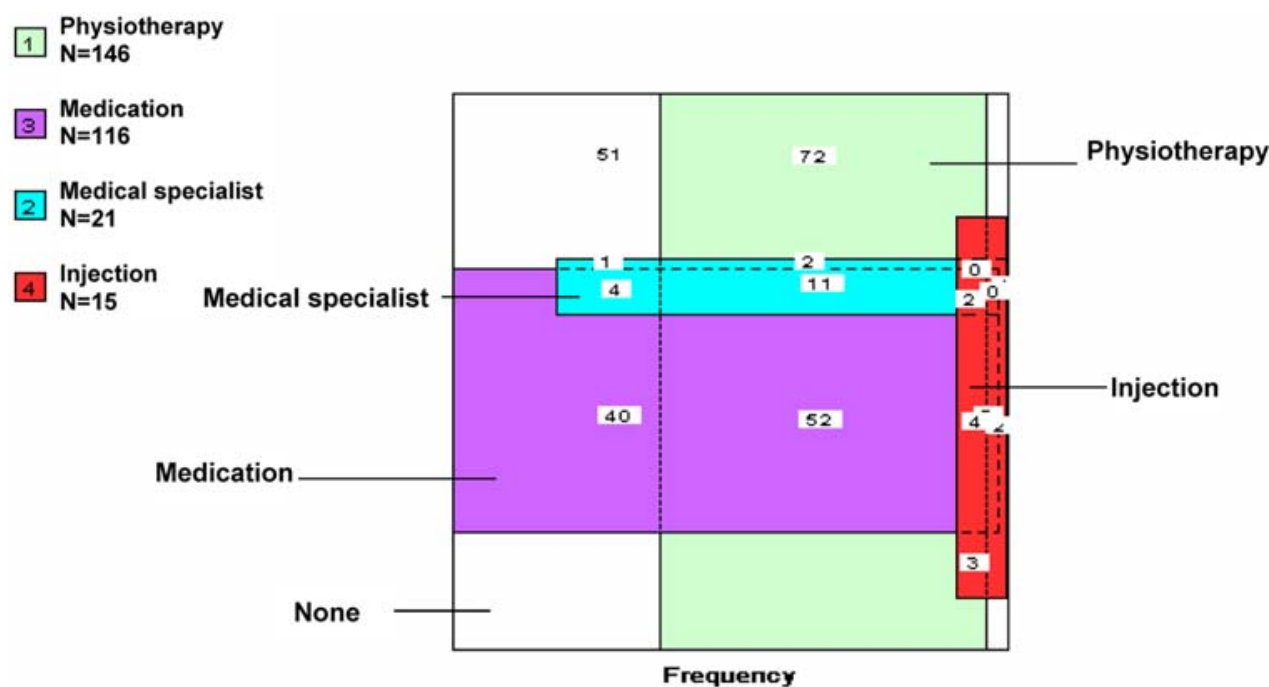

Fig. 2 Specific diagnoses and treatment up to 6 months after the first GP consultation

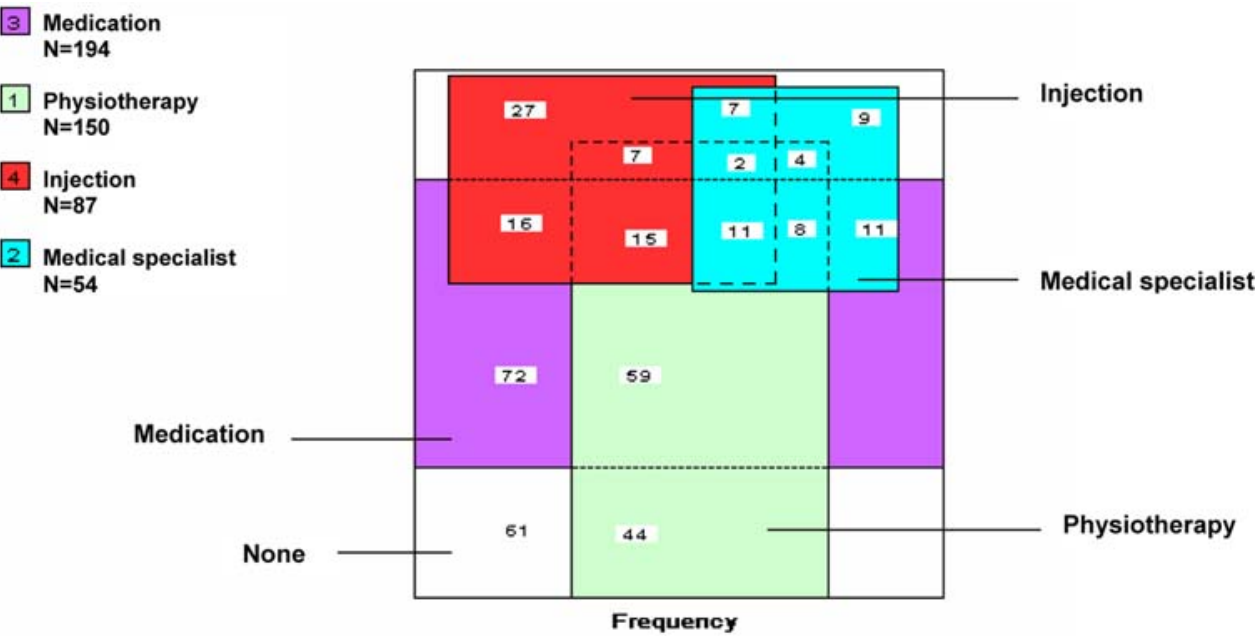

Karels et al. evaluated the contents of physical therapy treatment in patients with non-traumatic arm, neck and shoulder complaints. They reported that most patients were treated with exercise therapy (93\%), massage $(87 \%)$ or a combination of both. In $30 \%$ of the patients, the treatment included physical modalities (such as ultrasound), and in $20 \%$ of the patients treatment included manipulation techniques [17].

\section{Differences in management}

Differences between the specific and non-specific diagnostic groups, on the distribution of referral to a medical specialist, was mainly due to specific diagnoses of forearm, wrist and hand. This may be for confirmation of the diagnosis, non-conservative treatment or reassuring the patient, but we have no data to verify this hypothesis.
The application of corticosteroid injections, mainly in specific shoulder diagnoses, is according to the practice guideline. However, the effect of the application of corticosteroid injections in epicondylitis, shoulder pain and carpal tunnel syndrome, seems to be mainly restricted to short term relief of symptoms [3, 5, 24].

For the largest subgroup with 'non-specific diagnoses' in arm, neck, and shoulder, no guidelines are available. That patients with non-specific diagnoses are more frequently referred for physiotherapy than patients with specific diagnoses, seems in line with the distribution of the diagnoses in a cohort study in physiotherapy practice where the majority of the study population were patients with nonspecific diagnoses [17].

However, a Cochrane review reported only limited evidence for the effectiveness of exercises in patients with chronic non-specific neck and shoulder complaints [28]. 
Variance within a certain diagnostic group may (partly) be explained by differences in hindrance, as mentioned in both guidelines for epicondylitis [1] and shoulder pain [2]. Another reason may be lack of solid evidence in favour of one of the studied treatment options in the total range of non-traumatic arm, neck and shoulder complaints. Although there is limited or short term effect (mainly shortterm pain relief) of some of the treatment options, solid evidence in favour of any one of the studied treatment options in this population lacks [27]. The lack of clear evidence of effective treatments may leave more room for personal preferences of both GP and patient.

Besides, patient- and other complaint-characteristics, such as age, employment or psychosocial factors may lead to differences in management decisions as well. These factors probably contribute to the GP's prognosis [11], which may influence management. Therefore, we checked the univariate association of the 6-months prognosis according to the GP with the five different management options. Poor GP-prognosis showed a positive association with additional diagnostic tests (OR 2.7; 1.7-4.6) and with referral for physiotherapy (OR 2.1; 1.5-3.0). The association with referral for medical specialist care (OR 1.6; $0.7-$ 3.5) was not significant. Besides the low OR, the prevalence of the outcome was also low. Prescription of medication (OR 1.1; 0.9-1.5) and application of corticosteroid injection (OR 0.9; 0.6-1.1), however, did not show a relation with the expected prognosis. This is in line with short-term relief of symptoms as treatment goal in these options.

\section{Strengths and the limitations of this study}

This is the first study to compare the management of different diagnostic groups in non-traumatic arm, neck and shoulder complaints. Some of the diagnostic subgroups are large (e.g. shoulder complaints and epicondylitis) and others are very small, reflecting everyday clinical practice $[4,10]$. Therefore, the reported management mainly represents these larger diagnostic subgroups.

In the present study, we used the diagnosis registered at the first consultation. However, in some cases the initial diagnosis may have changed after time; due to difficult differential diagnostics within the limited consultation time or the need for additional diagnostic tests, or true changes [30], what may affect the therapeutic approach. Because of this, and the fact that the diagnosis was realised in a nonstandardised manner, we cannot rule out some misclassification. This may have resulted in less contrast between the specific and non-specific group.

In the present study, 15 out of the 682 participants received two diagnoses of whom 8 participants received two specific diagnoses within the same region, which may indicate difficult differential diagnostics. Besides, seven participants were diagnosed with both impingement syndrome and a specific forearm diagnosis (epicondylitis/tendonitis/carpal tunnel syndrome). We chose to work with the most centrally located diagnosis, here impingement syndrome.

Due to the response time of 8 weeks, in $21 \%$ of the patients the data on management at baseline were not restricted to a single consultation.

Another issue was that the follow-up questionnaire referred to the previous 6 months. We accounted for possible overlap of treatment options due to recollection of information by reporting 'management up to 6 months'.

In the small group that is referred to a medical specialist, part of the reported decisions on management may be made on the specialists' own initiative.

A recent development in the Netherlands is that since January 2006, patients no longer need a referral for physiotherapy. This may have implications for the overall treatment in the future.

\section{Conclusions}

In non-traumatic arm, neck and shoulder complaints, analgesics and referral for physiotherapy were the treatment options most frequently used, followed by corticosteroid injections and referral for medical specialist care. Patients with a non-specific diagnosis were more frequently referred for physiotherapy and less frequently to a medical specialist compared to patients with a specific diagnosis. Corticosteroid injections were mainly applied in specific diagnoses (e.g. impingement syndrome, frozen shoulder, carpal tunnel and M. Quervain).

Future intervention studies could provide evidence of effective treatments, especially for the large group of nonspecific diagnoses, mainly located at the neck-shoulder region. Others may help to clarify the influence of variables, other than diagnoses, on the variance in management decisions between and within diagnostic groups.

Acknowledgments The authors thank the participating GPs and all the patients for their invaluable contribution to this study. Internal funding of Erasmus MC (Resolving Fund). The Funder had no role in the study design, the data collection, analyses, interpretation of results, writing the report or in submitting the paper. Competing interests: All authors declare that they have no competing interests.

Open Access This article is distributed under the terms of the Creative Commons Attribution Noncommercial License which permits any noncommercial use, distribution, and reproduction in any medium, provided the original author(s) and source are credited.

\section{Appendix}

Table 5 
Table 5 Appendix: The diagnoses included in the present study

\begin{tabular}{ll}
\hline Diagnoses & \\
\hline & $\begin{array}{l}\text { Number of } \\
\text { patients }\end{array}$ \\
\hline Specific complaints included in this study & \\
Cervical hernia & 5 \\
Subacromial impingement syndrome & 220 \\
$\quad$ (rotator cuff syndrome, tendinoses, bursitis) & \\
Frozen shoulder & 9 \\
Biceps tendinosis & 2 \\
Lateral/medial epicondylitis & 93 \\
Bursitis elbow & 3 \\
Osteoarthritis of elbow (no Rheumatoid arthritis) & 2 \\
Cubital tunnel syndrome & 2 \\
Peritendinitis/tenosynovitis flexors/extensors forearm & 13 \\
Quervain's syndrome & 13 \\
Guyon's tunnel syndrome & 5 \\
Radial tunnel syndrome & 1 \\
Carpal tunnel syndrome & 11 \\
Osteoarthritis of wrist or hand (no Rheumatoid arthritis) & 14 \\
Free body of wrist or hand & 1 \\
Raynaud's phenomenon and peripheral neuropathy in & 1 \\
combination with exposure to hand-arm vibration & \\
Trigger finger & 2 \\
Ganglion & 5 \\
Non-specific complaints & \\
All other arm, neck and shoulder complaints not & 280 \\
attributable to trauma or systemic diseases & \\
\hline
\end{tabular}

\section{References}

1. Guideline for Epicondylitis of the Dutch College of General Practitioners (2006) Available at: http://nhg.artsennet.nl/upload/ 104/standaarden/M60/start.htm. Accessed on 20 Jan 2006 [In Dutch]

2. Guideline for Shoulder Complaints of the Dutch College of General Practitioners (2006) Available at http://nhg.artsennet.nl/ upload/104/guidelines2/E08.htm. Accessed on 20 Jan 2006 [In Dutch]

3. Ashworth N (2006) Carpal tunnel syndrome. In: Clinical evidence, Issue 15. BMJ Publishing Group, London

4. Bot S, van der Waal JM, Terwee C et al (2005) Incidence and prevalence of complaints of the neck and upper extremity in general practice. Ann Rheum Dis 64(1):118-123

5. Buchbinder R, Green S et al (2006) Tennis elbow. In: Clinicalevidence, Issue 15. BMJ Publishing Group, London

6. Cardol M, van Dijk L, de Jong JD et al (2004) Tweede Nationale Studie naar ziekten en verrichtingen in de huisartspraktijk:huisartsenzorg: wat doet de poortwachter? NIVEL, Utrecht [In Dutch]

7. CBO, Guideline for management of Carpal Tunnel Syndrome (2006) Available at: http://www.cbo.nl/product/richtlijnen/ folder20021023121843/rl_cts_2006.pdf/view. Accessed on 11 Sep 2006 [In Dutch]
8. Côté P, Cassidy JD, Carroll L (2001) The treatment of neck and low back pain: who seeks care? who goes where? Med Care 39(9):956-967

9. Croft P, Pope D, Silman A (1996) The clinical course of shoulder pain: prospective cohort study in primary care. Primary Care Rheumatology Society Shoulder Study Group. BMJ 313(7057):601-602

10. Feleus A, Bierma-Zeinstra SM, Miedema HS et al (2007) Incidence of non-traumatic complaints of arm, neck or shoulder in general practice. Man Ther [Epub ahead of print]

11. Feleus A, Bierma-Zeinstra SM, Miedema HS et al (2007) Prognostic indicators for non-recovery of non-traumatic complaints at arm, neck and shoulder in general practice- 6 months follow-up. Rheumatology (Oxford) 46(1):169-176

12. Hagen KB, Bjørndal A, Uhlig T et al (2000) A population study of factors associated with general practitioner consultation for non-inflammatory musculoskeletal pain. Ann Rheum Dis 59(10):788-793

13. Haynes RB, Devereaux PJ, Guyatt GH (2002) Physicians' and patients' choices in evidence based practice. BMJ 324(7350): 1350

14. Hudak PL, Amadio PC, Bombardier C (1996) Development of an upper extremity outcome measure: the DASH (disabilities of the arm, shoulder and hand) [corrected]. The Upper Extremity Collaborative Group (UECG). Am J Ind Med 29(6):602-608

15. Huisstede BM, Miedema HS, Verhagen AP et al (2007) Multidisciplinary consensus on terminology and classification of complaints of arm, neck and/or shoulder. Occup Environ Med 64(5):313-319

16. James M, Stokes EA, Thomas E et al (2005) A cost consequences analysis of local corticosteroid injection and physiotherapy for the treatment of new episodes of unilateral shoulder pain in primary care. Rheumatology (Oxford) 44:1447-1451

17. Karels CH, Polling W, Bierma-Zeinstra SM et al (2006) Treatment of arm, neck and/or shoulder complaints in physiotherapy practice. Spine 31(17):E584-E589

18. Korthals-de Bos IB, Smidt N, van Tulder MW et al (2004) Cost effectiveness of interventions for lateral epicondylitis; results from a randomised controlled trial in primary care. Pharmacoeconomics 22(3):185-195

19. Luime JJ, Koes BW, Miedem HS et al (2005) High incidence and recurrence of shoulder and neck pain in nursing home employees was demonstrated during a 2-year follow-up. J Clin Epidemiol 58(4):407-413

20. Marshall RJ (2005) Scaled rectangle diagrams can be used to visualize clinical and epidemiological data. J Clin Epidemiol 58(10):974-981

21. Picavet HS, Schouten JS (2003) Musculoskeletal pain in the Netherlands: prevalences, consequences and risk groups, the DMC(3)-study. Pain 102(1-2):167-178

22. Rekola KE, Keinänen-Kiukaanniemi S, Takala J (1993) Use of primary health services in sparsely populated country districts by patients with musculoskeletal symptoms: consultations with a physician. J Epidemiol Community Health 47(2):153-157

23. Sluiter J, Rest KM et al (2000) Criteria document for evaluation of the work-relatedness of upper extremity musculoskeletal disorders. Final report. Joint programme for working life research in Europe. Amsterdam, Coronel Institute for Occupational and Environmental Health, University of Amsterdam, p 92

24. Speed C (2006) Clinical evidence, shoulder pain. BMJ 15

25. Struijs PA, Korthals-de Bos IB, van Tulder MW et al (2006) Cost effectiveness of brace, physiotherapy, or both for treatment of tennis elbow. Br J Sports Med 40:637-643

26. van der Windt DA, van der Heijden GJ, Scholten RJ et al (1995) The efficacy of non-steroidal anti-inflammatory drugs (NSAIDS) 
for shoulder complaints. A systematic review. J Clin Epidemiol 48(5):691-704

27. Van Tulder M, Malmivaara A, Koes B (2007) Repetitive strain injury. Lancet 26(369):1815-1822

28. Verhagen AP, Karels C, Bierma-Zeinstra SM et al (2007) Exercise proves effective in a systematic review of work-related complaints of the arm, neck or shoulder. J Clin Epidemiol 60(2):110-117
29. Walker-Bone K, Palmer KT, Reading I et al (2004) Prevalence and impact of musculoskeletal disorders of the upper limb in the general population. Arthritis Rheum 51(4):642-651

30. Winters JC, Sobel JS, Groenier KH et al (1999) The long-term course of shoulder complaints: a prospective study in general practice. Rheumatology (Oxford) 38(2):160-163 